International Journal of Instruction e-ISSN: 1308-1470 • www.e-iji.net

Article submission code: 20201230144934

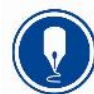

January $2022 \bullet$ Vol.15, No.1

p-ISSN: 1694-609X

pp. $39-54$

Received: 30/12/2020

Revision: 27/05/2021
Accepted: 25/06/2021

OnlineFirst: 04/10/2021

\title{
Influence of Facilitating and Hindering Variables of Academic Engagement in Spanish Secondary Students
}

\section{Marta Oporto Alonso}

Prof., PhD., first and corresponding author, Department of Psychology, Faculty of Psychology, Abat Oliba CEU University, CEU Universities, Spain, moportoa@uao.es

\section{Marina Fernández Andújar}

PhD., first author, Department of Psychology, Faculty of Psychology, Abat Oliba CEU University, CEU Universities, Spain, mfernandezan@uao.es

\section{Caterina Calderon}

PhD., Department of Clinical Psychology, and Psychobiology, Faculty of Psychology, University of Barcelona, Spain, ccalderon@ub.edu

Academic Engagement (AE) can explain part of the success of current educational programmes. This observational and prospective study aims to identify the facilitating and hindering psychosocial variables involved in AE. We included achievement goals and academic motivation as facilitating academic variables and perceived stress and social problems as hindering variables. The sample included 603 students who were consecutively recruited in ESO and Baccalaureate in schools in Barcelona. The inclusion criteria for the participants were as follows: to be enrolled in a year from 1st year of ESO to 2nd year of Baccalaureate; to have access to the average mark of the previous year and to complete the questionnaires in full. The following were administered: Utrecht Work Engagement Scale-Student version, Achievement Goal Questionnaire-Revised, Academic Motivation Scale, Perceived Stress Scale and Youth Self Report / 11-18. Linear regression analysis shows that the variables involved in the development and maintenance of AE were intrinsic motivation, mastery approach and extrinsic motivation whereas lack of motivation, perceived stress and social issues were hindering variables $(R 2=0.634$; $\mathrm{F}=98.793 ; \mathrm{p}=0.000)$. In conclusion, all these variables should be taken into account because they can contribute to academic engagement in students.

Keywords: academic engagement, achievement motivation, perceived stress, psychopathology, motivation

Citation: Alonso, M. O., Andújar, M. F., \& Calderon, C. (2022). Influence of facilitating and hindering variables of academic engagement in spanish secondary students. International Journal of Instruction, 15(1), 39-54. https://doi.org/10.29333/iji.2022.1513a 


\section{INTRODUCTION}

Finding out which factors either facilitate or hinder engagement is crucial if we are to promote our students' academic success (Martínez et al., 2016; Uludag, 2016). Engagement is a motivational factor that includes effort (high degree of effort shown in taking on tasks), dedication (enthusiasm and setting goals for work) and absorption (a feeling that time passes quickly and conformity with the task at hand) (Martin et al. 2021; Finn \& Zimmer, 2012; Carmona et al., 2019; Thomas \& Allen, 2021; Oporto et al., 2019). According to Salanova et al. (2012) the facilitators and hinderers of engagement, these have a direct influence on student performance and an indirect effect on their level of commitment.

Academic motivation and achievement goals have classically been included as facilitators of engagement (Amrollahi, 2021). There are three types of academic motivation in relation to students' basic needs: intrinsic motivation, extrinsic motivation and amotivation (Deci \& Ryan, 2016; Núñez et al., 2015; Skinner et al., 2014). Intrinsic motivation can be seen in those students who perform a task moved by factors within themselves, without external pressure, because they have given meaning to the activity, carrying out autonomous actions aimed at academic success. According to Deci \& Ryan (2016) intrinsic motivation is born from a need for competence and self-determination that drives individuals to gain knowledge, achievement and stimulate experiences. It implies that learning happens while experiencing pleasure or while trying to learn something new (Núñez et al., 2015). Extrinsic motivation implies taking on a task to achieve a reward (Vallerand et al., 2019). Amotivation represents a lack of motivation, since the person perceives a lack of control and a disconnect between their behaviour and its consequences (Vallerand et al., 2019; Deci \& Ryan, 2016). Therefore, if, according to the literature reviewed, motivation and engagement are related, it seems that those students who are motivated more intrinsically are those who will achieve higher levels of academic engagement (Deci \& Ryan, 2016; An, 2015; Christenson et al., 2012). Also, academic motivation of students can be observed through the desire, for example, to be actively involved in lectures and it can be measured using operational scales and observational rubrics, determination to overcome difficulties as well as the desire to recover and try again when they experience a failure (Hidajat et al., 2020).

Achievement motivation is the competency-based objective used to guide behaviour (Elliot \& Dweck, 2013). To date, few studies have addressed the relationship between achievement motivation and academic engagement. González-Valenzuela \& MartínRuíz (2016) showed that the motivation for academic achievement is related to academic performance (Valadez-Sierra et al., 2016). A recent meta-analysis that reviewed 189 studies on the link between the affective relationship of students and teachers and engagement and academic achievement concluded that there is indeed a relationship between the two (Roorda et al., 2011; Roorda et al., 2017). Related to this, it is important that teachers be familiar with, for example, different teaching styles, apply good transmission of knowledge and be nurturing to increase students' engagement (Khun-Inkeeree et al., 2021). 
Perceived stress and social problems in students are barriers to engagement (Grant et al., 2011). Perceived stress may be due to interactions with peers and teachers, the demands of academic work and school rules, as well as the connection between leisure spaces and schoolwork. In this sense, there is no scientific evidence associating perceived stress and academic engagement, nor was there any evidence of the influence of other events such as divorce, loss of employment or the death of a family member (Herbers et al., 2013). Similarly, it appears that stressful experiences in early adolescence are associated with low academic engagement and prosocial values, as well as symptoms of depression (Tolan et al., 2013; Wang \& Peck, 2013). Wang \& Fredricks (2014) noted a relationship between school children with lower rates of behavioural and emotional engagement in school and delinquent behaviour and substance abuse. The relationships between engagement and violent behaviour were two-way, while low behavioural and emotional engagement and the presence of more problematic behaviour were shown to be predictors of early school leaving. The relationship between socio-emotional functioning, substance abuse and engagement has also been described in the literature (Wigfield et al., 2015). In contrast, it appears that students with a high sense of social connection show better results in terms of achievement, engagement and positive attitudes (Pianta et al., 2012; Stroet et al., 2013; King, 2015; Wentzel \& Muenks, 2016).

To date, few studies have addressed the issue in the Spanish secondary and baccalaureate population, and some of the results are not consistent in this way; further research is needed to clarify this issue. This study aims to evaluate the ability of certain variables to explain engagement, both facilitating (school motivation and achievement goals) and hindering (perceived stress and social problems). It uses a sample of Spanish teenagers studying in ESO (Compulsory Secondary Education) and Baccalaureate.

\section{METHOD}

\section{Sample}

The design of this prospective study was cross-sectional and observational with a nonrandomly selected sample that included 603 students from 1st year to 4th year of ESO and Baccalaureate from 4 state schools providing compulsory secondary education in Barcelona. The total sample was obtained after applying the following inclusion criteria: to be enrolled in a year from 1st year of ESO to 2nd year of Baccalaureate; to have access to the average mark of the previous year and to complete the questionnaires in full. The exclusion criteria were the following: having some kind of disability that makes it difficult to read and understand the questions, being under 12 years of age and reporting fatigue or a physical condition that makes it difficult to complete the protocol. This study has been approved by the ethics committees of Abat Oliba CEU University in Barcelona and was conducted in accordance with the ethical standards of the Declaration of Helsinki. 


\section{Instruments}

Socio-demographic questionnaire. It included sociodemographic data on the adolescent (age, gender, current academic year and, in the case of Baccalaureate students, the chosen specialty was indicated, as well as whether or not they had repeated a year and, if they had, what year) and the family (level of schooling and occupation of the parents). With the variables of schooling level and occupation of the parents, the family socioeconomic level index was calculated following the Hollingshead indications (Hollingshead, 2011). The parents' level of education was divided into 7 categories, from no primary schooling to completed degree studies. Occupation was divided into 8 categories from unemployed to director and/or manager of a large company. The Socioeconomic Level ranges from 8 to 66 points and provides five indicators: low, medium-low, medium, medium-high and high.

Utrecht Work Engagement Scale-Student version (UWES-S-9; Schaufeli et al., 2002; Serrano et al., 2019): this is a Likert-type questionnaire comprising 9 items $(0=$ never; 3 $=$ regularly; $6=$ always) in which three factors are measured: effort, dedication and absorption. These three factors provide an overall engagement score. The full Spanish version of the scale was used. The validity, following Cronbach's alpha, is 0.89 to 0.97 (Schaufeli \& Bakker, 2004; Serrano et al., 2019)

Achievement Goal Questionnaire-Revised (AGQ-R; Elliot \& Murayama, 2008; Strunk, 2014): Likert-type questionnaire comprising 12 items with 4 subscales, so all items are classified in a range from 1 to 7 , where 7 indicates "always". These subscales are: mastery-approach goals (ex. "My aim is to completely master the material presented in class"), mastery-avoidance goals (ex. "My aim is to avoid learning less than I possibly could in this course"), performance-approach goals (ex. "I am striving to do well compared to other students in this course"), and performance-avoidance goals (ex. "My goal is to avoid performing poorly compared to others in class"). The full Spanish version of the scale was used (Sánchez-Rosas, 2015). The validity, following Cronbach's alpha, is, respectively, 0.84 in mastery-approach, 0.88 in performanceapproach, 0.92 in mastery-avoidance, 0.94 in performance-avoidance (Sánchez-Rosas, 2015).

Academic Motivation Scale (MAT; Núñez et al., 2005; 2010): this is a Likert-type questionnaire comprising 28 items, all with a score range of 1 to 7 , where 7 indicates "always". It measures three factors: Intrinsic Motivation (IM) (ex. "Because I feel pleasure and satisfaction when I learn new things"), Extrinsic Motivation (EM) (ex. "Because it will help me make a better decision regarding my career guidance") and Amotivation (AM) (ex. "I honestly don't know, I think I'm wasting my time in high school"). The full Spanish version of the scale was used. The validity, according to Cronbach's alpha, is 0.76 and 0.84 .

Perceived Stress Scale (PSS-10; Remor, 2006; Serrano \& Andreu, 2016): Likert-type questionnaire comprising 10 items (between 1 and 4 and where 4 indicates "yes, true" to one of the factors measured: level of perceived stress in the last month and degree to 
which life situations are described as stressful (ex. "In the past month, how often have you been affected by something that happened unexpectedly?"). The full Spanish version of the scale was used. The validity in the Spanish version following Cronbach's alpha was 0.87 (Remor, 2006).

Youth Self Report/11-18 (T-YSR; Achenbach \& Rescorla, 2000; Barcelata-Eguiarte \& Márquez-Caraveo, 2019): Likert type questionnaire comprising 40 items scored from 0 to 2 , where 2 indicates "yes, frequently". It consists of 4 subscales that analyse behavioural and emotional problems: anxiety/depression (ex. "I feel very lonely"), social problems (ex. "I disobey my parents"), attention problems (ex. "I can't focus or pay attention for long") and aggressive behaviour (ex. "I argue a lot"). 40 of the 103 items in the second part of the Spanish version of the questionnaire were used. Cronbach's alpha in a Spanish sample (Abad et al., 2000) was: 0.83 for depression/anxiety in boys and 0.82 in girls; 0.59 for aggressive behaviour in boys and 0.62 in girls; 0.59 for inattention in boys and 0.74 in girls, and 0.64 for social problems in boys and 0.70 in girls.

\section{Process}

School principals requested informed consent from participants' parents and were informed of the objectives of the study, as well as any concerns. Data collection was done through questionnaires carried out in classrooms. Students were told that the survey was voluntary, that they could withdraw at any time and that their responses were anonymous. A researcher and a teacher remained in the room during the administration of the questionnaires. The average time required to complete the questionnaire was approximately 20 minutes and it was conducted within regular school hours.

To analyse the relationship between academic engagement and the variables that facilitate and hinder it, Pearson's correlation was used for both the global sample and the analyses separated by gender. In addition, linear regression models were used to assess the specific contribution of academic engagement and its psychosocial variables. A value of $p<0.05$ was considered statistically significant for all analyses. The statistical analyses were conducted using the Statistical Package for the Social Sciences (SPSS) 23.0 for Windows (SPSS Inc., Chicago, Illinois, USA).

The sample included 603 students from the 1st year to the 4th year of ESO and Baccalaureate, $55.9 \%(\mathrm{n}=337)$ boys and $44.1 \%(\mathrm{n}=266)$ girls, with an average $(\mathrm{M})$ age of: 15.2 years; standard deviation (SD): 1.6 ; range $12-19$ years old. The average family socioeconomic level of the participants was 43.1 ( $\mathrm{SD}=11$; range from 13 to 66) which indicates that the students come from a medium-high family socioeconomic level. The demographic and socio-economic data of the participants are summarised in Table 1. 
Table 1

Demographic and socio-economic data of the sample $(n=603)$

\begin{tabular}{|c|c|c|}
\hline Variable & $\mathrm{n}$ & $\%$ \\
\hline \multicolumn{3}{|l|}{ Gender } \\
\hline Male & 337 & 55.9 \\
\hline Female & 266 & 44.1 \\
\hline Age in years $(\mathrm{M} ; \mathrm{SD})^{\mathrm{a}}$ & $15.2(1.6)$ & \\
\hline Socioeconomic Level of Familyb & $43.1(11)$ & \\
\hline \multicolumn{3}{|l|}{ School year } \\
\hline ESO 1 & 74 & 12.3 \\
\hline ESO 2 & 70 & 11.6 \\
\hline ESO 3 & 63 & 10.4 \\
\hline $\mathrm{ESO} 4$ & 167 & 27.7 \\
\hline Baccalaureate 1 & 145 & 24 \\
\hline Baccalaureate 2 & 84 & 13.9 \\
\hline
\end{tabular}

Note. $\mathrm{M}=$ Mean; $\mathrm{SD}=$ Standard deviation.

a The age range is between 12 and 19 years.

${ }^{b}$ Range of scores: 8-66.

\section{FINDINGS}

\section{Descriptive Statistics}

The descriptive statistics are shown in Table 2. No statistically significant differences were found between male and female students regarding the level of academic engagement $(\mathrm{t}=-0.543 ; \mathrm{p}=0.587)$.

Table 2

Descriptive statistics between study variables

\begin{tabular}{ll}
\hline & $\mathrm{M}(\mathrm{SD})$ \\
\hline UWES-S-9. Utrecht Work Engagement Scale-Student version & $3.5(1.1)$ \\
\hline Facilitating variables & \\
\hline AGQ-R. Performance-Approach goal & $3.7(1.5)$ \\
\hline AGQ-R. Mastery-Approach goal & $5.1(1.3)$ \\
\hline AGQ-R. Performance-Avoidance goal & $4.6(1.3)$ \\
\hline AGQ-R. Mastery-Avoidance goal & $4.0(1.5)$ \\
\hline MAT. Intrinsic Motivation & $4(1.1)$ \\
\hline MAT. Extrinsic motivation & $4.9(1.1)$ \\
\hline MAT. Amotivation & $1.8(1)$ \\
\hline Hindering Variables & \\
\hline PSS-10. Perceived stress & $18.5(6.4)$ \\
\hline T-YSR Depression/anxiety & $9.1(5.9)$ \\
\hline T-YSR Inattention & $7.2(3.3)$ \\
\hline T-YSR Aggressive behaviour & $3.0(2.3)$ \\
\hline T-YSR Social problems & $10.4(5.8)$ \\
\hline
\end{tabular}

Note. $\mathrm{M}=$ Mean; $\mathrm{SD}=$ Standard Deviation; UWES-S-9= Utrecht Work Engagement Scale-Student version; AGRQ-R= Achievement Goal Questionnaire-Revised; MAT= Academic Motivation Scale; PSS: Perceived Stress Scale; T-YSR: Youth Self Report/11-18. * $p<0.05$ 


\section{Multiple Analyses}

We sought to assess the potential of the variables taken into consideration to predict academic engagement using linear regression analysis. To achieve this objective, a linear stepwise regression was carried out, including those predictor variables with which academic engagement showed statistically significant correlations in the previous correlation analysis. Linear regression analysis shows that the variables involved in the development and maintenance of $\mathrm{AE}$ were intrinsic motivation, mastery approach and extrinsic motivation whereas lack of motivation, perceived stress and social issues were hindering variables $\left(\mathrm{R}^{2}=0.634 ; \mathrm{F}=98.793 ; \mathrm{p}=0.000\right)$. See table 3 .

Table 3

Results of the hierarchical regression between academic engagement and the rest of the variables of the study

\begin{tabular}{|c|c|c|c|c|c|}
\hline \multirow[t]{2}{*}{ Model } & \multicolumn{2}{|c|}{ Non-standardised coefficients } & \multicolumn{2}{|l|}{$\begin{array}{l}\text { Standardised } \\
\text { coefficients }\end{array}$} & \multirow[b]{2}{*}{ Sig. } \\
\hline & $\beta$ & Typical error & $\beta$ & $\mathrm{t}$ & \\
\hline \multicolumn{6}{|l|}{ Model 1} \\
\hline Constant & 0.597 & 0.164 & & 3.650 & 0.000 \\
\hline Intrinsic motivation & 0.741 & 0.039 & 0.719 & 19.012 & 0.000 \\
\hline \multicolumn{6}{|l|}{ Model 2} \\
\hline Constant & 1.405 & 0.196 & & 7.161 & 0.000 \\
\hline Intrinsic motivation & 0.664 & 0.038 & 0.645 & 17.273 & 0.000 \\
\hline Amotivation & -0.283 & 0.043 & -0.248 & -6.649 & 0.000 \\
\hline \multicolumn{6}{|l|}{ Model 3} \\
\hline Constant & 0.843 & 0.218 & & 3.858 & 0.000 \\
\hline Intrinsic motivation & 0.555 & 0.043 & 0.539 & 13.002 & 0.000 \\
\hline Amotivation & -0.248 & 0.042 & -0.218 & -5.974 & 0.000 \\
\hline Mastery approach & 0.182 & 0.035 & 0.213 & 5.145 & 0.000 \\
\hline \multicolumn{6}{|l|}{ Model 4} \\
\hline Constant & 1.236 & 0.233 & & 5.306 & 0.000 \\
\hline Intrinsic motivation & 0.557 & 0.042 & 0.541 & 13.370 & 0.000 \\
\hline Amotivation & -0.202 & 0.042 & -0.177 & -4.792 & 0.000 \\
\hline Mastery approach & 0.181 & 0.034 & 0.212 & 5.253 & 0.000 \\
\hline Stress & -0.027 & 0.006 & -0.146 & -4.196 & 0.000 \\
\hline \multicolumn{6}{|l|}{ Model 5} \\
\hline Constant & 0.864 & 0.257 & & 3.368 & 0.001 \\
\hline Intrinsic motivation & 0.508 & 0.044 & 0.493 & 11.592 & 0.000 \\
\hline Amotivation & -0.192 & 0.042 & -0.168 & -4.608 & 0.000 \\
\hline Mastery approach & 0.175 & 0.034 & 0.204 & 5.126 & 0.000 \\
\hline Stress & -0.027 & 0.006 & -0.148 & -4.316 & 0.000 \\
\hline Extrinsic motivation & 0.118 & 0.036 & 0.121 & 3.248 & 0.001 \\
\hline \multicolumn{6}{|l|}{ Model 6} \\
\hline Constant & 1.337 & 0.337 & & 3.970 & 0.000 \\
\hline Intrinsic motivation & 0.502 & 0.044 & 0.488 & 11.510 & 0.000 \\
\hline Amotivation & -0.180 & 0.042 & -0.158 & -4.314 & 0.000 \\
\hline Mastery approach & 0.165 & .034 & 0.194 & 4.848 & 0.000 \\
\hline Stress & -0.022 & 0.007 & -0.122 & -3.363 & 0.001 \\
\hline Extrinsic motivation & 0.139 & 0.037 & 0.143 & 3.726 & 0.000 \\
\hline Social problems & -0.009 & 0.004 & -0.080 & -2.152 & 0.032 \\
\hline
\end{tabular}

International Journal of Instruction, January $2022 \bullet$ Vol.15, No.1 


\section{DISCUSSION}

In this study, we have analysed the presence of academic engagement in adolescents in ESO and Baccalaureate, as well as the relationship between this and other variables such as academic and achievement motivation, stress and social problems. Specifically, it has been observed that the variables of intrinsic and extrinsic motivation, lack of motivation, mastery approach, stress and social problems are related to academic engagement.

Students in our sample obtained a mean score of 3.5 [Standard Deviation, $(\mathrm{SD})=1.1$, range 1 to 7] on the Academic Engagement Scale. This seems to indicate that the engagement reported by students, i.e. the degree of effort, enthusiasm and conformity with what they are doing, falls somewhere within the average range. Comparing these results with the study by Schaufeli \& Bakker (2003) - the latter with a sample of 12,631 subjects [mean $(\mathrm{M})=4.1, \mathrm{SD}=1.1]$. This degree of academic engagement is significantly higher than in the students we have sampled, however, it is noted that both scores fall within the mid-range of academic engagement. In addition, the subjects who participated in the above-mentioned study were all university students, a fact that may explain some of these differences in the outcome of our study, since it seems logical to assume academic engagement is a construct that generally tends to increase over the course of a student's academic life and, consequently, it is a dynamic and ongoing process (Hidajat et al., 2020)

As for academic engagement, men obtained an average score of $3.5(\mathrm{SD}=1.1)$ and women $3.5(\mathrm{SD}=1.1)$ and no significant differences were found based on gender $(\mathrm{t}=$ $0.543 ; \mathrm{p}=0.587$ ). These data would be in line with a recent validation study of a scale of engagement in Spain that found no differences in academic engagement based on gender (García-Ros et al., 2016; Wang et al., 2011). There are other studies that detected differences in the level of engagement in academic performance among female primary school students (Yu, 2021), with a higher level of engagement in girls (Oga-Baldwin \& Nakata, 2017), however, our sample is composed of secondary school and Baccalaureate students, a fact that distinguishes the samples of the two studies.

In this same line, other authors have indicated that academic engagement, regardless of type, appears to be higher in women compared to men (Ayub et al., 2017; Wang \& Eccles, 2013). However, Barkatsas et al. (2009) indicated that emotional and behavioural engagement was more closely associated with greater success in mathematics in men than in women. In view of these inconclusive results, we believe that further research is needed to clarify which variables influence academic engagement and to what extent, and how this knowledge can be applied to increase student success in current academic programmes.

One of the main findings of this study was that academic engagement can be predicted to a greater extent by intrinsic motivation. In this sense our data seems to be in line with a relevant study other research such as that of Blumendfeld et al. (2006), where it is highlighted, that intrinsic motivation is a necessary condition for engagement since it allows learning to happen while experiencing pleasure or trying to learn something new 
(Núñez et al., 2005). Behind intrinsic motivation, we can identify three other motivational variables that can predict engagement, which are amotivation, a mastery approach and extrinsic motivation. It should be noted that amotivation, understood as the lowest level of motivation, contributes negatively to predicting engagement, that is, as students perceive a greater lack of control in the relationship between their behaviour and their consequences, engagement falls (Núñez et al., 2005). The predictive model also indicates that a certain level of extrinsic motivation (with $\beta=0.143$ ) is necessary to be able to predict academic engagement, something that coincides with previous research carried out by Vallerand et al. (2019). All these data would be in accordance with the recent study of Hidajat et al. (2020), which indicates that students' academic motivation was a dynamic and ongoing process, which was affected by intrinsic (from amotivation to intrinsic motivation) and extrinsic factors such as social support, goal orientation, achievement anxiety, and self-efficacy.

Finally, our predictive model confirms that students who set goals that imply a high need for achievement, intrinsic motivation or high level of interest in the task and who focus on achieving competencies at a personal level are the most engaged with their studies. This is in line with what has already been mentioned, in the sense that a preference for mastery-approach goals is linked to focussing on success as the core of the activity, promoting hope and positive emotions as the drive behind the activity (Elliot \& McGregor, 2001; Méndez-Giménez et al., 2016; Datu et al., 2021).

In this predictive model, obstacles to academic engagement include stress and social problems in the global sample. Thus, if students perceive as stressful events in the school dynamic, such as interactions with peers and teachers, the demands of academic work and school rules, exams and compulsory work, along with concerns about their academic future, their level of engagement will fall, in line with work by Grant et al. (2011), Moses \& Villodas, 2017; Moksnes et al. (2014), Fiorilli et al., 2017 \& GarciaRos et al. (2016). As for social problems, the predictive model suggests that if students perceive their relationships with peers as negative, this affects their level of academic engagement. In this regard, in line with the above, we can predict that if students do not perceive support from their teachers, parents and peers (thus indicating social problems) their level of engagement will decrease, as seen in Estell \& Perdue (2013) and Rowe et al. (2016). Specifically, the level of engagement of students taken as a whole increases when faced with a task or challenge presented as a means of obtaining knowledge, surpassing themselves and perceiving it as a stimulating experience (intrinsic motivation).

\section{CONCLUSIONS}

In summary, as we have seen, the level of engagement of students seems to increase if they first seek to adequately solve a task in order to demonstrate to themselves that they can do it, and thereby surpass themselves, setting aside comparisons with their peers (mastery approach). Furthermore, engagement increases, though to a lesser extent, if, when facing a school challenge, students are motivated not only to achieve an end, but 
to obtain a reward (achievement approach). Our research allows us to provide some pedagogical guidelines aimed at increasing the level of engagement of students or to be included in the training of teachers. Finally, the detection of social problems typical of the affective and social world of adolescents, and subsequent interventions to manage them, is another key area in increasing levels of academic engagement. In this regard, we should take into account academic resilience (Martin et al., 2013; Nicoll, 2014) and its measurement (Ramdani et al., 2020) for detection and intervention by teachers, family, peers and the school's counselling team, as it may be relevant in addressing the academic engagement in these students (Barkley \& Major, 2020).

This study, though based on a large and homogeneous sample, presents some limitations that should be considered if findings are to be generalised. In this regard, a potential line of research for the future could be to explore whether there are differences in terms of gender and age in academic engagement and the other variables explored, as well as to include different types of schools (public and private) located in different areas of Barcelona. Future research could also expand on the data collected regarding academic engagement by using assessment strategies and instruments that further deepen the three components of academic engagement: absorption, effort and dedication, specifically in secondary and Baccalaureate students. Similarly, it could include other variables that have not been considered in this study, such as personality, cognitive performance or other social variables, which would provide a much richer picture of their relationship with engagement. The recognition that we are dealing with a population in a particular stage of development and maturation has led to differences with other studies. A longitudinal study could clarify whether indeed many of the variables studied were subject to processes of gradual change over time, observing the behaviour of these differences across various years, particularly with regard to academic engagement.

\section{REFERENCES}

Abad, J., Forns, M., Amador, J. A., \& Martorell, B. (2000). Fiabilidad y validez del Youth Self Report en una muestra de adolescentes. Psicothema, 12(1), 4954. http://www.psicothema.com/psicothema.asp?id=252

Achenbach, T. M., \& Rescorla, L. A. (2000). Manual for the ASEBA Preschool Forms \& Profiles. University of Vermont, Research Center for Children, Youth, \& Families.

Amrollahi Beyooki, A., Sepahmansour, M., \& Ghanbaipanah, A. (2021). Structural Model of Students' Academic Motivation based on the Teacher-Student Relationship, School Attachment, and Metacognitive Awareness through SelfMediation. International Journal of Pediatrics,9(2), 13077-13090. https://dx.doi.org/10.22038/IJP.2020.49977.3988.

An, B. (2015). The role of academic motivation and engagement on the relationship between dual enrollment and academic performance. Journal of Higher Education, 86, 98-126. https://dx.doi.org/10.1353/jhe.2015.0005 
Ayub, A., Yunus, A., Mahmud, R., Salim, N. R. \& Sulaiman, T. (2017). Differences in students' mathematics engagement between gender and between rural and urban schools. AIP Conference Proceedings, (1795)1, 1-6. https://doi.org/10.1063/1.4972169

Barkatsas, A. T., Kasimatis, K., \& Gialamas, V. (2009). Learning secondary mathematics with technology: exploring the complex interrelationship between students' attitudes, engagement, gender and achievement. Computers \& Education, 52(3), 562570. https://doi.org/10.1016/j.compedu.2008.11.001

Barkley, E. F., \& Major, C. H. (2020). Student engagement techniques: A handbook for college faculty. John Wiley \& Sons.

Barcelata-Eguiarte, B. E., \& Márquez-Caraveo, M. E. (2019). Estudios de Validez del Youth Self Report/11-18 en Adolescentes Mexicanos. Revista Iberoamericana de Diagnóstico y Evaluación-e Avaliação Psicológica, 50(1), 107-22. https://doi.org/10.21865/RIDEP50.1.09

Blumenfeld, P. C., Kempler, T. M., \& Krajcik, J. S. (2004). Motivation and cognitive engagement in learning environments. In R. K. Sawyer (Ed.), The Cambridge handbook of the learning sciences (pp. 475-488). Cambridge University Press.

Carmona-Halty, M., Salanova, M., Llorens, S., \& Schaufeli, W. B. (2019). Linking positive emotions and academic performance: The mediated role of academic psychological capital and academic engagement. Current Psychology, 1-10. https://doi.org/10.1007/s12144-019-00227-8

Christenson, S. L., Reschly, A. L., \& Wylie, C. (2012). Handbook of research on student engagement. Springer.

Datu, J. A. D., Valdez, J. P. M., \& Yang, W. (2021). The academically engaged life of mastery-oriented students: Causal ordering among positive emotions, mastery-approach goals, and academic engagement. Revista de Psicodidáctica (English ed.). https://doi.org/10.1016/j.psicoe.2021.02.001

Deci, E. L., \& Ryan, R. M. (2016). Optimizing students' motivation in the era of testing and pressure: A self-determination theory perspective. In Building autonomous learners (pp. 9-29). Springer.

Elliot, A. J., \& McGregor, H. A. (2001). A 2 x 2 achievement goal framework. Journal of personality and social psychology, 80(3), 501-519. https://doi.org/10.1037/00223514.80.3.501

Elliot, A. J., \& Murayama, K. (2008). On the measurement of achievement goals: critique, illustration, and application. Journal of Educational Psychology, 100(3), 613628. https://doi.org/10.1037/0022-0663.100.3.613

Elliot, A. J., \& Dweck, C. S. (Eds.). (2013). Handbook of competence and motivation. Guilford Publications. 
Estell, D. B., \& Perdue, N. H. (2013). Social support and behavioral and affective school engagement: the effects of peers, parents, and teachers. Psychology in the Schools, 50(4), 325-339. https://doi.org/10.1002/pits.21681.

Estévez, I., Rodríguez, S., Valle, A., Regueiro, B., \& Piñeiro, I. (2016). Incidencia de las metas académicas del alumnado de secundaria en su gestión motivacional. Aula Abierta, 44(2), 83-90.

Finn J.D., \& Zimmer K.S. (2012). Student Engagement: What Is It? Why Does It Matter?. In: Christenson S., Reschly A., Wylie C. (eds), Handbook of Research on Student Engagement (97-132). Springer. https://doi.org/10.1007/978-1-4614-2018-7_5

Fiorilli, C., De Stasio, S., Di Chiacchio, C., Pepe, A., \& Salmela-Aro, K. (2017). School burnout, depressive symptoms and engagement: Their combined effect on student achievement. International Journal of Educational Research, 84, 1-12. https://doi.org/10.1016/j.ijer.2017.04.001

García-Ros, R., Pérez-González, F., \& Fuentes Durán, M. (2016). Análisis del estrés académico en la adolescencia: efectos del nivel educativo y del sexo en Educación Secundaria Obligatoria. Información Psicológica, 110, 212. https://dx.medra.org/10.14635/IPSIC.2015.110.3

González-Valenzuela, M. J., \& Martín-Ruíz, I. (2016). Motivación de logro y lenguaje escrito en adolescentes españoles. Anales de Psicología, 32(2), 466473. http://dx.doi.org/10.6018/analesps.32.2.201561

Grant, K. E., McMahon, S. D., Duffy, S. N., Taylor, J. J., \& Compas, B. E. (2011). Stressors and mental health problems in childhood and adolescence. In R. J. Contrada \& A. Baum (Eds.), The handbook of stress science: Biology, psychology, and health (p. 359-372). Springer.

Herbers, J. E., Reynolds, A. J., \& Chen, C. C. (2013). School mobility and developmental outcomes in young adulthood. Development and psychopathology, 25(2), 501-515. https://doi.org/10.1017/S0954579412001204

Hidajat, H. G., Hanurawan, F., Chusniyah, T., \& Rahmawati, H. (2020). Why I'm Bored in Learning? Exploration of Students' Academic Motivation. International Journal of Instruction, 13(3), 119-136. https://doi.org/10.29333/iji.2020.1339a

Hollingshead, A. B. (2011). Four factor index of social status. In: Smith, P. (ed), Yale Journal of Sociology, $8, \quad$ (p. 21-52). Yale University. https://sociology.yale.edu/sites/default/files/files/yjs_fall_2011.pdf

Khun-Inkeeree, H., Pimjan, L., \& Adelaja, A. A. (2021). Moderating Effect of Thai Teachers' Perspective on the Relationship between Teaching Perspectives, Students' Engagement. International Journal of Instruction, 14(1), 631-646. https://doi.org/10.29333/iji.2021.14138a

King, R. B. (2015). Sense of relatedness boosts engagement, achievement, and wellbeing: A latent growth model study. Contemporary Educational Psychology, 42, 26-38. https://doi.org/10.1016/j.cedpsych.2015.04.002 
Martín, A. B., del Carmen Pérez-Fuentes, M., Jurado, M. D. M., Martínez, Á. M., Márquez, M. D. M., Sisto, M., \& Linares, J. J. G. (2021). Emotional Intelligence and Academic Engagement in Adolescents: The Mediating Role of Self-Esteem. Psychology Research and Behavior Management, 14, 307-316. https://doi.org/10.2147/PRBM.S302697

Martin, A. J., Ginns, P., Brackett, M. A., Malmberg, L. E., \& Hall, J. (2013). Academic buoyancy and psychological risk: Exploring reciprocal relationships. Learning and Individual Differences, 27, 128-133. https://doi.org/10.1016/j.lindif.2013.06.006

Martínez, I. M., González, J. P., \& Meneghel, I. (2016). Take care of well-being: how facilitators and engagement predict performance of university students. Multidisciplinary Journal for Education, Social and Technological Sciences, 3(1), 100-117. https://doi.org/10.4995/muse.2016.3751

Méndez-Giménez, A., Estrada, J. A. C., Fernández-Río, J., Alonso, D. M. \& Saborit, J. A. P. (2016). 3x2 Achievement Goals, Self-Determined Motivation and Life Satisfaction in Secondary Education. Journal of Psychodidactics, 21(2), 116. https://doi.org/10.1387/revpsicodidact. 15035

Moksnes, U. K.; Espnes, G. A., \& Haugan, G. (2014). Stress, sense of coherence and emotional symptoms in adolescents. Psychology \& Health, 29(1), 3249. https://doi.org/10.1080/08870446.2013.822868

Moses, J. O., \& Villodas, M. T. (2017). The potential protective role of peer relationships on school engagement in at-risk adolescents. Journal of Youth and Adolescence, 46(11), 2255-2272. https://doi.org/10.1007/s10964-017-0644-1

Nicoll, W. G. (2014). Developing transformative schools: A resilience-focused paradigm for education. International Journal of Emotional Education, 6(1), 47-65. https://doi.org/10.1037/e573262013-031

Núñez, J. L., Fernández, C., León, J., \& Grijalvo, F. (2015). The relationship between teacher's autonomy support and students' autonomy and vitality. Teachers and Teaching, 21(2), 191-202. https://doi.org/10.1080/13540602.2014.928127

Núñez, J.L., Martín-Albo, J., \& Navarro, J.G. (2005). Validación de la versión española de la Échelle de Motivation en Éducation. Psicothema, 17(2), 344349. https://www.psicothema.com/psicothema.asp?id=3110

Núñez, J. L., Martín-Albo, J., Navarro, J. G., \& Suárez, Z. (2010). Adaptación y validación de la versión española de la Escala de Motivación Educativa en estudiantes de educación secundaria postobligatoria. Estudios de Psicología, 31(1), 89-100. https://doi.org/10.1174/021093910790744590

Oga-Baldwin, W. Q., \& Nakata, Y. (2017). Engagement, gender, and motivation: a predictive model for Japanese young language learners. System, 65, 151-163. https://doi.org/10.1016/j.system.2017.01.011

Oporto Alonso, M., Fernández, M., \& Porras, S. (2019). Academic Engagement in students of Secondary and Bachelor Education: towards a complete understanding of the 
term. Multidisciplinary Journal of School Education, (15), 45-54. https://DOI 10.14632/mjse.2019.15.45

Pianta, R. C., Hamre, B. K., \& Allen, J. P. (2012). Teacher-student relationships and engagement: Conceptualizing, measuring, and improving the capacity of classroom interactions. In Christenson, S. L., Reschly, A. L., \& Wylie C. (Eds.), Handbook of research on student engagement (p. 365-386). Springer Science \& Business Media.

Ramdani, R., Hanurawan, F., Ramli, M., Lasan, B. B., \& Afdal, A. (2020). Development and Validation of Indonesian Academic Resilience Scale Using Rasch Models. International Journal of Instruction, 14(1), 105-120. https://doi.org/10.29333/iji.2021.1417a

Remor, E. (2006). Psychometric Properties of a European Spanish Version of the Perceived Stress Scale (PSS). The Spanish Journal of Psychology, 9(1), 8693. https://doi.org/10.1017/s1138741600006004

Roorda, D. L.; Koomen, H. M.; Spilt, J. L. \& Oort, F. J. (2011). The influence of affective teacher-student relationships on students' school engagement and achievement a meta-analytic approach. Review of Educational Research, 81(4), 493-529.

Roorda, D. L., Jak, S., Zee, M., Oort, F. J., \& Koomen, H. M. (2017). Affective teacher-student relationships and students' engagement and achievement: A metaanalytic update and test of the mediating role of engagement. School Psychology Review, 46(3), 239-261.

Rowe, M. L., Ramani, G. B., \& Pomerantz, E. M. (2016). Parental Involvement and Children's motivation and achievement. In Wentzel, K.R., \& Miele, D.B. (Eds.), Handbook of Motivation at School (p. 459-476). Routledge.

Salanova, M., Martínez, I., \& Llorens, S. (2012). Success breeds success, especially when self-efficacy is related with an internal attribution of causality. Estudios de Psicología, 33(2), 151-165. https://doi.org/10.1174/021093912800676420

Sánchez Rosas, J. (2015). Validation of the achievement goal questionnaire - revised in Argentinean university students (A-AGQ-R). International Journal of Psychological Research, 8 (1), 10-23. https://doi.org/10.21500/20112084.641

Schaufeli, W. B., \& Bakker, A. B. (2003). UWES-Utrecht Work Engagement Scale Preliminary Manual. Occupational Health Psychology Unit Utrecht University.

Schaufeli, W. B., \& Bakker, A. B. (2004). Job demands, job resources, and their relationship with burnout and engagement: A multi-sample study. Journal of Organizational Behavior, 25(3), 293-315. https://doi.org/10.1002/job.248

Schaufeli, W. B., Salanova, M., González-Romá, V., \& Bakker, A. B. (2002). The measurement of engagement and burnout: A two sample confirmatory factor analytic approach. Journal of Happiness $\quad$ Studies, 3(1), 92. https://doi.org/10.1023/A:1015630930326 
Schunk, D. H., \& Mullen, C. A. (2012). Self-efficacy as an engaged learner. In Christenson, S. L., Reschly, A. L., \& Wylie C. (Eds.), Handbook of research on student engagement (p. 219-235). Springer.

Serrano, C., \& Andreu, Y. (2016). Inteligencia emocional percibida, bienestar subjetivo, estrés percibido, engagement y rendimiento académico en adolescentes. Journal of Psychodidactics, 21(2), 357-374. https://doi.org/10.1387/revpsicodidact.14887

Serrano, C., Andreu, Y., Murgui, S., \& Martínez, P. (2019). Psychometric properties of Spanish version student Utrecht Work Engagement Scale (UWES-S-9) in high-school students. The Spanish journal of psychology, 22. https://doi.org/10.1017/sjp.2019.25

Skinner, E., Pitzer, J., \& Brule, H. (2014). The Role of Emotion in Engagement, Coping and the Development of Motivational Resilience. In Pekrun, R., \& Linnenbrink-Garcia L. (Eds.), International Handbook of Emotions in Education (p. 331-346). Routledge.

Stroet, K., Opdenakker, M. C., \& Minnaert, A. (2013). Effects of need supportive teaching on early adolescents' motivation and engagement: a review of the literature. Educational Research Review, 9, 6587. https://doi.org/10.1016/j.edurev.2012.11.003

Strunk, K. K. (2014). A factor analytic examination of the achievement goal questionnaire-revised supports a three-factor model. Psychological reports, 115(2), 400-414. https://doi.org/10.31235/osf.io/4cf6k

Tolan, P., Lovegrove, P., \& Clark, E. (2013). Stress mitigation to promote development of prosocial values and school engagement of inner-city urban African American and Latino youth. American journal of orthopsychiatry, 83(2), 289298. https://doi.org/10.1111/ajop.12038

Thomas, C. L., \& Allen, K. (2021). Driving engagement: investigating the influence of emotional intelligence and academic buoyancy on student engagement. Journal of Further Higher and Education, 45(1), 107-119. https://doi.org/10.1080/0309877x.2020.1741520

Uludag, O. (2016). The mediating role of positive affectivity on testing the relationship of engagement to academic achievement: an empirical investigation of tourism students. Journal of Teaching in Travel \& Tourism, 16(3),63-

177. https://doi.org/10.1080/15313220.2015.1123130

Valadez-Sierra, M.D., Valdés-Cuervo, Á.A., Aguiñaga-Maldonado, L.A., MoralesGonzález, J.S., Cervantes-Arreola, D.I., \& Zambrano-Guzmán, R. (2016). Diferencias en el locus de control y la motivación al logro en estudiantes de secundaria con altas habilidades intelectuales y promedio. Revista de Educación y Desarrollo, 37, 3338. https://www.cucs.udg.mx/revistas/edu_desarrollo/anteriores/37/37_Valadez.pdf

Vallerand, R. J., Pelletier, L.G., Blais, M.R., Brière, N.M., Senècal, C., \& Vallières, E. F. (1993). On the Assessment of Intrinsic, Extrinsic, and Amotivation in Education: evidence on the Concurrent and Construct Validity of the Academic Motivation 
Scale. Educational and Psychological Measurement, 53(1), 159172. https://doi.org/10.1177/0013164493053001018

Vallerand, R. J., Carbonneau, N., \& Lafreniere, M. A. K. (2019). La théorie de l'autodétermination et le modèle hiérarchique de la motivation intrinsèque et extrinsèque: perspectives intégratives. In: Carré, P., \& Fenouillet, F. Traité de psychologie de la motivation. (p. 47-66). Dunod.

Wang, M. T., \& Eccles, J. S. (2013). School context, achievement motivation, and academic engagement: a longitudinal study of school engagement using a multidimensional perspective. Learning and Instruction, 28, 12-23. https://doi.org/10.1016/j.learninstruc.2013.04.002.

Wang, M. T. \& Peck, S. C. (2013). Adolescent educational success and mental health vary across school engagement profiles. Developmental Psychology,49(7), 12661276. https://doi: $10.1037 / \mathrm{a} 0030028$

Wang, M. T., \& Fredricks, J. A. (2014). The reciprocal links between school engagement, youth problem behaviors, and school dropout during adolescence. Child development, 85(2), 722-737. https://doi.org/10.1111/cdev.12138

Wang, M. T., Willett, J. B., \& Eccles, J. S. (2011). The assessment of school engagement: examining dimensionality and measurement invariance by gender and race/ethnicity. Journal of School Psychology, 49(4), 465-480. https://doi.org/10.1016/j.jsp.2011.04.001

Wentzel, K. R., \& Muenks, K. (2016). Peer influence on students' motivation, academic achievement, and social behavior. In: Wentzel, K. R., Ramani, G. Handbook of social influences in school contexts: Social-emotional, motivation, and cognitive outcomes. ( $\mathrm{p}$. 13-30). Routledge.

Wigfield, A., Eccles, J. S., Fredricks, J. A., Simpkins, S., Roeser, R. W., \& Schiefele, U. (2015). Development of achievement motivation and engagement. In Lamb, M.E., \& Lerner, R. M (Eds.), Handbook of child psychology and developmental science: Socioemotional processes. (p. 657-700). John Wiley \& Sons, Inc. https://doi.org/10.1002/9781118963418.childpsy316

Yu, J., McLellan, R., \& Winter, L. (2021). Which Boys and Which Girls Are Falling Behind? Linking Adolescents' Gender Role Profiles to Motivation, Engagement, and Achievement. Journal of youth and adolescence, 50(2), 336-352. https://doi.org/10.31234/osf.io/9p54t

$(*)$ This article is the result of financing granted to the project: "Fomento de la resiliencia en la educación primaria: innovación y formación continua del profesorado (ANDREIA)" (PID2019-111032RB-I00) and the project: "Programa REDICE 2020 (código REDICE 20-2401)" University of Barcelona (Spain). 